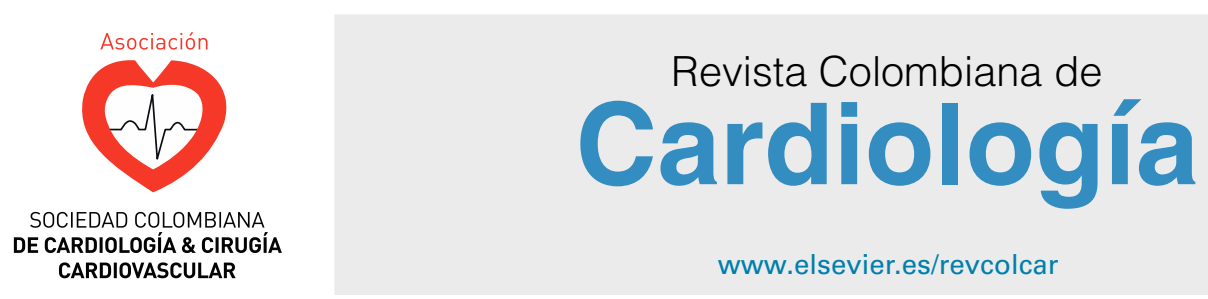

\title{
EDITORIAL
}

\section{What does the International Committee of Medical Journal Editors of the European Society of Cardiology suggest regarding scientific article authorship?}

\author{
Darío Echeverri
}

Editor in Chief, Revista Colombiana de Cardiología

For the last several years, the Revista Colombiana de Cardiología has been developing a relationship with the EditorsŃetwork of the European Society of Cardiology, placing it in a privileged position in Latin America and compared with other national and regional scientific journals.

This Network is committed to fostering the implementation of high quality editorial standards among the cardiovascular journals of the European Society of Cardiology member associations. It plays a relevant role in the dissemination of original scientific research and supports education and the standardization of clinical practice. In this regard, the EditorsNietwork endorses the recommendations of the International Committee of Medical Journal Editors and continually updates its uniform requirements document (formerly known as the Vancouver directives) for manuscripts submitted to biomedical journals. These include recommendations for the conduct, reporting, editing and publication of academic papers. Accordingly, the Revista Colombiana de Cardiología previously published Data Sharing: A New Editorial Initiative of the International Committee of Medical Journal Editors. Implications for the Editors' Network. ${ }^{1}$

Recently, the Revista Colombiana de Cardiología was invited to simultaneously publish Alfonso A, et al.ś document From Credit to Accountability. Reflections from the EditorsNetwork. On behalf of the Editors' Network,

Correo electrónico: decheverri@cardioinfantil.org
European Society of Cardiology (ESC) Task Force. In this review, the International Committee of Medical Journal Editors emphasized that authorship is a serious commitment to the responsibility of appearing as the author of a scientific article. This document recommends the following for author selection, based on four requirements:

1. Substantial contributions to the project conception or design or to the acquisition, analysis or interpretation of data for the paper.

2. Paper writing or significant critical review of the scholarly content.

3. Final approval of the version to be published.

4. Agreement to be responsible for all aspects of the paper and a guarantee that questions regarding the accuracy or integrity of any part of the paper will be adequately investigated and resolved.

The particular concept of this manuscript is to emphasize each author's responsibility to defend the integrity of the whole paper. Each author should understand the full extent of the paper, know which co-authors are responsible for specific contributions, and trust in the ability and integrity of the co-authors. If questions should arise regarding any aspect of a study, all the authors will be responsible for investigating and guaranteeing an answer to the problem, which will then be presented to the respective editor.

Without a doubt, this relationship of the Revista Colombiana de Cardiología with the International Committee of 
Medical Journal Editors strengthens us, and simultaneously publishing this document along with fifty European scientific journals will have a positive effect on the continuous improvement of our scientific articles for the benefit of our readers and research groups.

\section{Reference}

1. Alfonso F, Adamyan K, Artigou JY, Aschermann M, Boehm M, Buendía A, et al. Data Sharing: A New Editorial Initiative of the International Committee of Medical Journal Editors. Implications for the Editors' Network. Rev Colomb Cardiol. 2017;24:2014-210. 